\title{
KELIMPAHAN KEANEKARAGAMAN MANGROVE PANTAI INDAH, DESA TELUK LECAH, BENGKALIS
}

\author{
Yeeri Badrun \\ Fakultas Mipa dan Kesehatan Universitas Muhammadiyah Riau \\ Email: yeeri.badrun@umri.ac.id
}

\section{ABSTRAK}

Penelitian ini Juni sampai Juli 2015 berlokasi di Pantai Indah Desa Teluk Lecah, Kecamatan Rupat, Kabupaten Bengkalis, Provinsi Riau. Penelitian untuk mengetahui keanekaragaman tumbuhan mangrove. Metode yang digunakan dalam penelitian ini adalah metode survei dengan 3 stasiun. Hasil penelitian menunjukkan pada Stasiun I terdapat 5 jenis pohon, total individu sebanyak 47 dan Indeks Keanekaragaman $\left(H^{\prime}\right)=1,56$; Stasiun II terdapat 5 jenis pohon, total individu sebanyak 50 dan Indeks Keanekaragaman $\left(\mathrm{H}^{\prime}\right)=1,41$; Stasiun III terdapat 5 jenis pohon, total individu sebanyak 46 dan Indeks Keanekaragaman $\left(H^{\prime}\right)=1,58$. Sedangkan pada Stasiun I terdapat 7 jenis anakan, total individu sebanyak 138 dan Indeks Keanekaragaman $\left(\mathrm{H}^{\prime}\right)=1,15$; Stasiun II terdapat 7 jenis anakan, total individu sebanyak 119 dan Indeks Keanekaragaman $\left(H^{\prime}\right)=1,92$; Stasiun III terdapat 7 jenis anakan, total individu sebanyak 89 dan Indeks Keanekaragaman $\left(\mathrm{H}^{\prime}\right)=1,91$.

Kata Kunci : Keanekaragaman, Mangrove, Rupat, Bengkalis

\section{PENDAHULUAN}

\section{Latar Belakang}

Hal ini menunjukan bahwa ekosistem mangrove merupakan salah satu antara habitat lahan basah pantai yang mengalami tekanantekanan pembangunan baik secara langsung maupun tidak langsung (Kelompok Kerja Mangrove Tingkat Nasional, 2013). Provinsi Riau memiliki sekitar 2,25\% dari luas mangrove yang ada di Indonesia. Luas mangrove di Provinsi Riau 206.292,642 hektar dan Bengkalis 55.292,937 hektar, (Marhalim et al., 2014). Desa Teluk Lecah terletak di Pulau Rupat Kecamatan Rupat Kabupaten Bengkalis yang memiliki luas Wilayah $\pm 90 \mathrm{~km}^{2}$ (Profil Desa Teluk Lecah, 2014), di mana belum pernah dilakukan penelitian tentang hutan mangrove. Maka berdasarkan latar belakang di atas penulis melakukan penelitian tentang Keanekaragaman Vegetasi Hutan Mangrove dan Kelimpahan Bivalvia di Pantai Indah Desa Teluk Lecah Kecamatan Rupat Kabupaten Bengkalis Provinsi Riau.

\section{Tujuan Penelitian}

Penelitian ini bertujuan untuk mengetahui kondisi lingkungan di Pantai Indah Desa Teluk Lecah melalui analisis keanekaragaman vegetasi mangrove.

\section{Manfaat Penelitian}

Manfaat dari penelitian ini diharapkan untuk mendapatkan data dasar dan informasi awal tentang keanekaragaman vegetasi mangrove yang dapat menggambarkan kondisi lingkungan di Pantai Indah sehingga dapat berguna dalam upaya mengelola dan melindungi sumberdaya hayati mangrove di daerah tersebut.

\section{METODOLOGI PENELITIAN}

Penelitian ini dilakukan pada bulan Juni sampai Juli 2015 di Pantai Indah Desa Teluk Lecah Kecamatan Rupat Kabupaten Bengkalis Provinsi Riau. Identifikasi Bivalvia dan analisis data dilaksanakan di Laboratorium Biologi Fakultas MIPA dan Kesehatan Universitas Muhammadiyah Riau. 


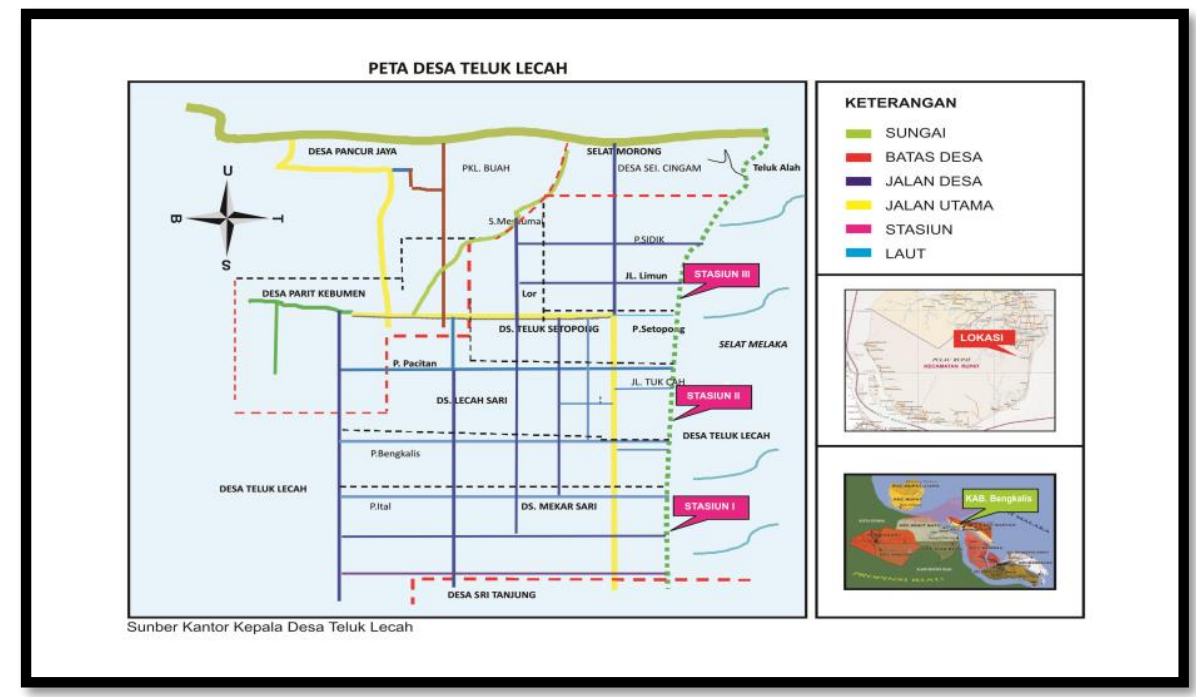

Gambar 1. Peta Lokasi Penelitian

Metode yang digunakan dalam penelitian ini adalah metode survei, di mana ekosistem mangrove di Pantai Indah Desa Teluk Lecah dijadikan sebagai lokasi pengamatan untuk memperoleh data primer. Selanjutnya dilakukan analisa di Laboratorium Biologi Fakultas MIPA dan Kesehatan UMRI. Parameter kualitas lingkungan yang di ukur yaitu: $\mathrm{pH}$ Tanah, $\mathrm{pH}$ Air, Suhu Tanah, Suhu Air, Salinitas Perairan, Kelembaban Udara.

Lokasi penelitian dibagi menjadi 3 stasiun, Stasiun I terletak di Dusun Mekar Sari, stasiun II terletak di Dusun Lecah Sari dan stasiun III terletak di Dusun Teluk Setopong. Pengamatan vegetasi mangrove strata pohon dengan diameter batang $>10 \mathrm{~cm}$ dilakukan pada plot yang berukuran $10 \mathrm{~m} \times 10 \mathrm{~m}$. Di dalam plot tersebut dibuat sub plot yang berukuran $2 \mathrm{~m}$ x 2 m untuk pengamatan vegetasi mangrove strata anakan, dengan mencatat nama jenis dan jumlah individu masing-masing jenis. Diameter mangrove diukur pada ketinggian $1,3 \mathrm{~m}$ atau diameter setinggi dada ( Diameter at Breast Height/DBH ). Untuk jenis yang tidak dapat diidentifikasi di lapangan, sampel jenis-jenis mangrove dibuat herbarium selanjutnya diidentifikasi menggunakan buku karangan Noor et al. (2006) di Laboratorium Biologi Fakultas Mipa dan Kesehatan Universitas Muhammadiyah Riau.

\section{Analisis Data Mangrove dan Bivalvia}

Analisis data untuk mengetahui keanekaragaman jenis tumbuhan dengan menggunakan indeks Shannon-Winner adalah :

$$
\mathrm{H}^{\prime}=-\sum[(\mathrm{ni} / \mathrm{N}) \ln (\mathrm{ni} / \mathrm{N})]
$$

Keterangan : H' = Indeks Shannon ni $=$ Nilai penting

$\mathrm{N}=$ Jumlah total nilai penting

Nilai keragaman $\left(\mathrm{H}^{\prime}\right)$ berkisar antara 0 - >3 dengan kriteria (a) 0-1 tergolong rendah, (b) 1-3 tergolong sedang, dan (c) $>3$ tergolong tinggi.

Perhitungan besarnya nilai Struktur dan Komunitas Mangrove diukur berdasarkan Saparinto, (2007), yaitu:

\section{Kerapatan}

Kerapatan adalah jumlah individu suatu jenis tumbuhan dalam satuan luas.

$$
\begin{gathered}
\text { Kerapatan }(\mathrm{K}) \text { suatu jenis }=\frac{\text { Jumlah individu suatu jenis }}{\text { Luas seluruh petak contoh }} \\
\text { Kerapatan Relatif }(\%)=\frac{\text { Frekuensi suatu jenis }}{\text { Kerapatan total seluruh jenis }} \times 100 \%
\end{gathered}
$$




\section{Frekuensi (Penyebaran)}

Penyebaran ( Frequency) adalah suatu nilai yang menunjukan penyebaran suatu jenis dari sejumlah petak contoh.

$$
\begin{aligned}
& \text { Kerapatan }(F) \text { suatu jenis }=\frac{\text { Jumlah plot yang ditempati suatu jenis }}{\text { Jumlah seluruh plot }} \\
& \text { Frekuensi Relatif }(\%)=\frac{\text { Frekuensi suatu jenis }}{\text { Kerapatan total seluruh jenis }} \times 100 \%
\end{aligned}
$$

\section{Dominansi (Kerimbunan)}

Dominansi adalah proporsi permukaan tanah yang ditutupi oleh proyeksi vertikal tajuk tumbuhan.

$$
\begin{gathered}
\text { Kerapatan (D)suatu jenis }=\frac{\text { Luas bidang dasar suatu jenis }}{\text { Luas seluruh petak contoh }} \\
\text { Dominasi Relatif }(\%)=\frac{\text { Dominasi suatu jenis }}{\text { Dominasi seluruh jenis }} \times 100 \%
\end{gathered}
$$

\section{Indeks Nilai Penting (INP) (\%)}

a. Untuk tingkat pohon $\mathrm{INP}=\mathrm{KR}+\mathrm{FR}+\mathrm{DR}$

b. Untuk tingkat anakan adalah INP $=\mathrm{KR}+\mathrm{FR}$

Menurut Fachrul (2011), nilai penting suatu jenis mangrove mempunyai nilai maksimum 300 . Nilai penting ini memberi gambaran pengaruh suatu jenis tumbuhan mangrove dan peranan suatu jenis tumbuhan mangrove dalam komunitas mangrove.

Analisa data yang dilakukan adalah menghitung kelimpahan Bivalvia:

$\mathrm{K}=\mathrm{n} / \mathrm{A}$

Keterangan: $\mathrm{K}=$ Kelimpahan Populasi (ind/m2)

$$
\begin{aligned}
& \mathrm{n}=\text { Jumlah Individu } \\
& \mathrm{A}=\text { Luas Total }(\mathrm{m} 2)
\end{aligned}
$$

\section{HASIL DAN PEMBAHASAN}

\section{Keadaan Umum Lokasi penelitian}

Gambaran umum lokasi penelitian Pantai Indah berada di tiga wilayah dusun yaitu:

1. Dusun Mekar Sari memiliki luas wilayah \pm $30 \mathrm{~km}^{2}$ dengan jumlah penduduk 891 jiwa, letak geografis dusun ini sebelah Utara berbatasan dengan Dusun Lecah Sari, sebelah Selatan berbatasan dengan Desa Sri Tanjung, sedangkan sebelah Timur Dusun Mekar Sari terdapat pantai Indah dan hutan mangrove. Mayoritas mata pencarian harian masyarakat adalah sebagai petani dan nelayan. Substrat di stasiun I ini substrat berlumpur dan hutan mangrove di stasiun ini terlihat sudah mulai berkurang dan mulai terganggu.

2. Dusun Lecah Sari memiliki luas wilayah \pm 30 $\mathrm{km}^{2}$ dengan jumlah penduduk 672 jiwa, letak geografis dusun ini sebelah Selatan batasan Dusun Mekar Sari. Sebelah Utara berbatasan dengan Dusun Teluk Setopong, sedangkan sebelah Timur Dusun Lecah Sari terdapat Pantai Indah dan hutan mangrove. Mayoritas mata pencariannya harian masyarakat adalah sebagai petani dan nelayan. Substrat di stasiun II ini substrat lumpur dan hutan mangrove di stasiun ini terlihat sudah berkurang dan terganggu.

3. Dusun Teluk Setopong memiliki luas wilayah $\pm 30 \mathrm{~km}^{2}$ dengan jumlah penduduk 823 jiwa. Letak geografis dusun ini, sebelah Selatan berbatasan Dusun Lecah Sari, sedangkan sebelah Barat berbatasan dengan Desa Parit Kabumen. Sedangkan Sebelah Timur dusun ini terdapat Pantai Indah dan hutan mangrove. Mayoritas mata pencariannya harian masyarakat adalah sebagai petani dan nelayan. Substrat di stasiun III ini substrat lumpur dan hutan mangrove distasiun ini terlihat sudah mulai berkurang terganggu.

\section{Keanekaragaman Jenis Tumbuhan Mangrove \\ Pada penelitian ini ditemukan 7 jenis tumbuhan mangrove yaitu: Rhizophora apiculata, Xylocarpus granatum, Scyphiphora hydrophyllacea, Sonneratia ovata, Lumnitzera}


racemosa, Nypa fruticans dan Acrostichum speciosum. Tumbuhan mangrove ini dapat dikelompokkan menjadi 5 strata pohon dan 7 strata anakan (Tabel 1).

Tabel 1. Jenis-jenis Tumbuhan Mangrove yang Ditemukan pada Hutan Mangrove Desa Teluk Lecah

\begin{tabular}{|l|l|l|l|}
\hline No. & Famili & Nama Spesies & Nama Lokal \\
\hline 1. & Rhizophoraceae & Rhizophora apiculata $* * *$ & Bakau Putih \\
\hline 2. & Meliaceae & Xylocarpus granatum $* * *$ & Nyirih \\
\hline 3. & Rubiaceae & Scyphiphora hydrophyllacea $* * *$ & Cingam \\
\hline 4. & Sonneratiaceae & Sonneratia ovata $* * *$ & Sesop \\
\hline 5. & Combretaceae & Lumnitzera racemosa $* * *$ & Kedabu \\
\hline 6. & Arecaceae & Nypa fruticans $*$ & Nipah \\
\hline 7. & Pteridaceae & Acrostichum speciosum $*$ & Piai \\
\hline
\end{tabular}

Keterangan: $* *=$ Pohon

$$
* \text { = Anakan }
$$

Tabel 1 menunjukkan bahwa $R$. apiculata, $X$. granatum, S. hydrophyllacea, S. ovata dan $L$. racemosa merupakan jenis tumbuhan mangrove yang ditemukan pada strata pohon dan anakan. Hal ini dikarenakan kondisi substrat yang cocok untuk pertumbuhan ke lima jenis tersebut dan perlindungan dari arus yang kuat. Susana et al., (2015) menjelaskan kategori pohon yang memiliki nilai rata-rata indeks nilai penting tertinggi adalah Rhizophora apicullata 47,543\% yang mana kondisi daerah perairan memiliki tekstur tanah yang berlumpur. Bila dibandingkan dengan penelitian Siahaan (2014), tentang komposisi mangrove Desa Sungai Alam Kecamatan Bengkalis tercatat 7 jenis dari 5 famili yaitu: Rhizophoraceae, Avicenniaceae, Meliaceae, Sonneratiaceae, Combretaceae dengan jenisnya yaitu: $L$. racemosa, $X$. granatum, Avicennia alba, $R$. Apiculata, $R$. Mucronata, $R$. Stylosa dan Sonneratia alba. Maka sebaran famili dan jenis mangrove pada ekosistem mangrove Desa Teluk Lecah memiliki sebaran famili dan jenis tumbuhan yang lebih banyak dari pada yang terdapat di Desa Sungai Alam.

\section{Parameter Kualitas Lingkungan}

Hasil pengukuran parameter kualitas lingkungan di Pantai Indah Desa Teluk Lecah yaitu $\mathrm{pH}$ tanah berkisar antara $6-7, \mathrm{pH}$ air 7, Suhu air berkisar antara $29^{\circ} \mathrm{C}-32{ }^{\circ} \mathrm{C}$, Kelembaban udara berkisar antara $40 \%-50 \%$, Salinitas berkisar antara $12 \%$ - $15 \%$, sedangkan Suhu tanah berkisar antara $27^{\circ} \mathrm{C}-30^{\circ} \mathrm{C}$ (Tabel 3).

Berdasar hasil pengukuran parameter lingkungan dikawasan penelitian diketahui bahwa stasiun I, II dan III memiliki nilai parameter yang hampir sama. Faktor lingkungan yang mempengaruhi habitat mangrove yang terdapat di Pantai Indah Desa Teluk Lecah yaitu: $\mathrm{pH}$ tanah Berkisar antara $6-7, \mathrm{pH}$ air 7 , Suhu Tanah berkisar anatara $27^{\circ} \mathrm{C}-30^{\circ} \mathrm{C}$, Suhu air berkisar antara $29^{\circ} \mathrm{C}-32^{\circ} \mathrm{C}$, Kelembaban berkisar antara $40 \%-50 \%$, sedangkan salinitas berkisar antara 12\%o - 15\%. Saparinto (2007), faktor lingkungan yang sangat berhubungan dengan habitat tumbuhan mangrove anatara lain, pasang surut menentukan Zonasi komunitas mangrove. Tumbuhan mangrove tumbuh subur didaerah estuari dengan salinitas $10 \%-30 \%$. Suhu yang baik untuk tumbuhan mangrove tidak kurang dari $20^{\circ} \mathrm{C}$, sedangkan suhu diatas $40^{\circ} \mathrm{C}$ cenderung tidak berpengaruh nyata pada tingkat kehidupan mangrove. Kisaran cahaya optimal untuk pertumbuhan mangrove adalah 3000 $3800 \mathrm{kkal} / \mathrm{m}^{2} / \mathrm{hari}$.

\section{Perbandingan \\ Keanekaragaman Mangrove Strata Pohon Maupun Anakan}

Perbandingan keanekaragaman mangrove pada masing-masing stasiun baik pada strata pohon maupun anakan pada Gambar 2. 


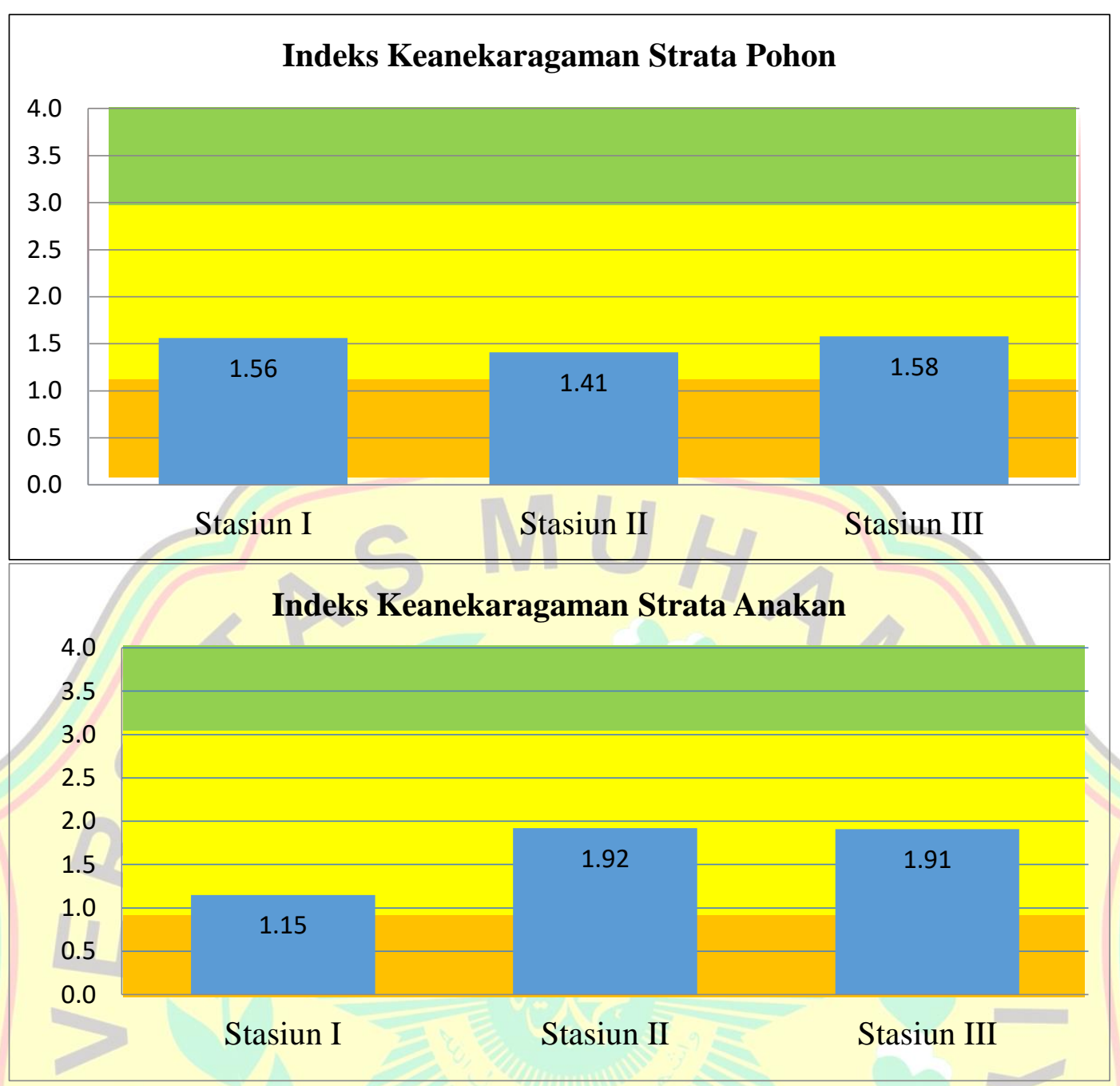

Gambar 2. Grafik Perbandingan Keanekaragaman Mangrove Strata Pohon Maupun Anakan Pada 3 Stasiun

Keanekaragaman mangrove di seluruh stasiun yang diamati baik strata ponon dan anakan menunjukan Indeks Keanekaragaman yang berkisar antara 1,41 sampai dengan 1,58 untuk strata pohon dan 1,15 sampai dengan 1,92 untuk strata anakan. Seluruh Nilai Indeks Keanekaragaman tingkat pohon dan anakan tergolong sedang. Hal ini menggambarkan kondisi lingkungan di lokasi penelitian sudah mulai terganggu akibat adanya aktivitas manusia. Hal ini terlihat di lokasi penelitian yang terdapat kegiatan penebangan mangrove dan tempat lalu lintas masyarakat ke arah pantai. Penelitian ini sejalan dengan hasil penelitian Susanto et al., (2013), yang menyatakan dampak dari aktivitas nelayan dan pembagunan perumahan menjadikan keberadaan mangrove di sekitar Jembatan
Suramadu Sisi Surabaya semakin terdesak dan semakin berkurang luasnya.

\section{KESIMPULAN DAN SARAN}

\section{Kesimpulan}

Dari penelitian yang telah dilakukan, dapat disimpulkan bahwa :

1. Ditemukan 5 jenis strata pohon dan 7 jenis strata anakan yaitu, $R$. apiculata, $X$. granatum, S. hydrophyllacea, S. ovata, $L$. racemosa, $N$. fruticans dan A. speciosum.

2. Stasiun I terdapat 5 jenis Strata pohon, dengan Indeks Keanekaragaman $\left(\mathrm{H}^{\prime}\right)=1,56$; dan 7 jenis strata anakan dengan $\left(H^{\prime}\right)=1,15$.

3. Stasiun II terdapat 5 jenis Strata pohon, dengan $\left(H^{\prime}\right)=1,41$; dan 7 jenis strata anakan dengan $\left(H^{\prime}\right)=1,92$. 
4. Stasiun III terdapat 5 jenis strata pohon, dengan $\left(\mathrm{H}^{\prime}\right)=1,58$; dan 7 jenis strata anakan dengan $\left(H^{\prime}\right)=1,91$.

\section{Saran}

Disarankan untuk penelitian selanjutnya agar melakukan penelitian lanjutan untuk membandingkan kerapatan mangrove dan kelimpahan Bivalvia. Kemudian penulis juga menyarankan kepada masyarakat Desa Teluk Lecah agar menjaga kelestarian hutan mangrove agar kelimpahan Bivalvia terjaga dan tidak punah.

\section{Ucapan Terimakasih}

Penulis mengucapkan terimakasih kepada Ibu Novia Gesriantuti yang telah membantu melakukan analisis, evaluasi dan koreksi pelaksanaan penelitian ini. Ucapan terimakasih juga disampaikan pada Darmaji yang telah membantu pelaksanaan survai dan pengambilan sampel di lapangan dan analisis di laboratorium.

\section{DAFTAR PUSTAKA}

Marhalim, Zulfan. S. U, dan M. Tang. 2014. Strategi Pemberdayaan Kelompok Masyarakat Pengawas Upaya Pelestarian Mangrove di Kabupaten Bengkalis. Pusat Penelitian Lingkungan Hidup Universitas Riau

Noor. Y. R, M. Khazali, dan I. N. N Suryadiputra 2006. Panduan Pengenalan Mangrove di
Indonesia. Wetlands Internasional Indonesia Programme. Bogor

Kantor Desa Teluk Lecah. 2014, Profil Desa Teluk Lecah, Kecamatan Rupat Kabupten Bengkalis

Pramudji, 2001. Ekosistem Hutan Mangrove dan Peranannya Sebagai Habitat Berbagai Fauna Aquatik. Jurnal Oseana Volume 26 (4) : Hal 13 - 23

Saparinto, C. 2007. Pendayagunaan Ekosistem Mangrove. Penerbit Dahara Prize. Semarang.

Siahaan, R, M. 2014. Hubungan Kerapatan Mangrove dengan Kelimpahan Bivalvia di Desa Sungai Alam Kecamatan Bengkalis Kabupaten Bengkalis Provinsi Riau. Skripsi tidak diterbitkan. Fakultas Perikanan Dan Ilmu Kelautan. Universitas Riau. Pekanbaru.

Susanto, A, H. Thin, S. Hery, P. 2013. Struktur Komunitas Mangrove di Sekitar Jembatan Suramadu Sisi Surabaya. Jurnal Bioscientiae Volume 10 (1) : Hal $1-10$

Susana, Raza'i, T. S, Welani, W. R, 2015. Struktur Vegetasi Mangrove di Sungai Ladi Kelurahan Bugis Kecamatan Tanjung Pinang Kota Provinsi Kepulauan Riau. Jurnal Umrah.ac.id. Diakses pada tanggal 24 agustus 2015 